\title{
A Low Ratio of Red/Far-Red in the Light Spectrum Accelerates Senescence in Nest Leaves of Platycerium bifurcatum
}

\author{
Jakub Oliwa, Andrzes Kornas* and Andrzes Skoczowski ${ }^{* *}$ \\ Institute of Biology, Pedagogical University of Cracow, \\ Podchorażych 2, 30-084 Kraków, Poland
}

Received June 10, 2017; revision accepted September 18, 2017

\begin{abstract}
The fern Platycerium bifurcatum is a valuable component of the flora of tropical forests, where degradation of local ecosystems and changes in lighting conditions occur due to the increasing anthropogenic pressure. In ferns, phytochrome mechanism responsible for the response to changes in the value of R/FR differs from the mechanism observed in spermatophytes. This study analyzed the course of ontogenesis of nest leaves in P. bifurcatum at two values of the R/FR ratio, corresponding to shadow conditions (low R/FR) and intense insolation (high R/FR). The work used only non-destructive research analysis, such as measurements of reflectance of radiation from the leaves, their blue-green and red fluorescence, and the chlorophyll $a$ fluorescence kinetics. This allowed tracing the development and aging processes in the same leaves. Nest leaves are characterized by short, intense growth and rapid senescence. The study identified four stages of development of the studied leaves related to morphological and anatomical structure and changing photochemical efficiency of PSII. Under the high R/FR ratio, the rate of ontogenesis of the leaf lamina was much slower than under the low R/FR value. As shown, the rapid aging of the leaves was correlated with faster decline of the chlorophyll content. It was shown that leaf senescence was accompanied by accumulation of polyphenols, anthocyanins and carotenoids on the basis of reflectance and fluorescence measurements in the blue-green range.
\end{abstract}

Keywords: chlorophyll $a$ fluorescence; fern; nest leaves; photomorphogenesis; R/FR ratio; reflectance

\begin{abstract}
Abbreviations:
Area - surface area above the chlorophyll fluorescence induction curve; ARI - anthocyanin reflectance index; BRI - browning reflectance index; $\mathrm{CRI}_{1}$ - carotenoid reflectance index; $\mathrm{DI}_{0} / \mathrm{RC}$ - total energy dissipation not trapped by the PSII reaction center; $\mathrm{ET}_{0} / \mathrm{RC}$ - rate of electron transfer by the active PSII reaction center; $\mathrm{F}_{\mathrm{v}} / \mathrm{F}_{0}$ - maximum efficiency of the water-splitting reaction of the donor side of PSII; $\mathrm{F}_{\mathrm{v}} / \mathrm{F}_{\mathrm{m}}$ - maximum quantum yield of PS II; $\mathrm{H}-\mathrm{R} / \mathrm{FR}$ higher value of the red/far red ratio; L-R/FR - lower value of the red/far red ratio; PAR - photosynthetically active radiation; PI - PSII vitality index; PSII - photosystem II; $Q_{A}$ - plastochinon $Q_{A}$; RC - reaction center; RC/ABS - reaction center density ratio in terms of chlorophyll; R/FR - photon intensity between $660-670 \mathrm{~nm} /$ photon intensity between $725-735 \mathrm{~nm} ; \mathrm{TR}_{0} / \mathrm{RC}$ - energy trapping of one active reaction center; WBI - water band index.
\end{abstract}

\section{INTRODUCTION}

Sunlight determines not only the photochemical reactions of the light phase of photosynthesis, but also carries important biological information on the current state of the external environment. This information allows acclimation to changing environmental conditions already at an early stage of ontogeny, inter alia, by the activation of genes responsible for regulating growth and developmental processes, not directly related to photosynthesis (Kraepiel et al., 2001; Kodis et al., 2004). These include, for example, coloration of leaves, shoot growth or physio-morphological changes associated with tissue aging (Schaefer and Nagy, 2006). The quality of light, understood as the

\footnotetext{
*Corresponding authors, emails: anko@up.krakow.pl, skoczowski@ifr-pan.krakow.pl
} 
spectral composition, should be attributed a special role in the process of photomorphogenesis. The specific qualitative ratio of red to far-red waves (R/FR) in the white light spectrum regulates growth processes in plants. In photosynthetic organisms, this phenomenon is possible, among others, thanks to the presence of substantial quantities of phytochromes both in the cytoplasm and in nuclei of cells in actively growing tissue (Kircher et al., 1999; Yamaguchi et al., 1999). However, the mechanism of action of phytochromes seems to be different in various groups of photosynthetic organisms (Rösler et al., 2010). In spermatophytes, phytochrome is activated by red light and is partly transferred to the cell nucleus, taking part in the regulation of gene expression and giving rise to metabolic pathways that play a signaling function in photomorphogenic processes (Neff et al., 2000). This is made possible by the isomerization of the chromophore group of the phytochrome and the conformational change of its protein portion, which allow interaction with other cell modulators (Ponting and Aravind, 1997). However, part of the activated phytochrome pool remains within the cytoplasm and plays control functions only at the biochemical level. This is evidenced by the high speed of some phytochrome reactions (Rösler et al., 2010). However, in ferns, it was suggested that the phytochrome is located exclusively in the cytoplasm, without translocation to the nucleus, similarly as in mosses (Wada, 1988). In addition, at an early stage of gametophyte development in ferns, reactions related to phototropism and chloroplast relocation that depend on the $\mathrm{R} / \mathrm{FR}$ ratio are regulated - as in mosses - outside the nucleus (Kadota and Wada, 1999). The effect of light during morphogenesis is possible probably due to the simultaneous functioning of at least several receptors, which allows the course of several, often complementary, parallel reactions (Kendrick and Kronenberg, 1994). Hybrid photoreceptors called "superchromium" with common characteristics of phytochrome and phototropin, showing photoreversibility with respect to red and far red, were found in different species of ferns (Briggs and Olney, 2001). They can play an important role in ferns growing in shadow conditions (Kawai et al., 2003).

The diploid form of Platycerium bifurcatum, constituting the dominant generation, has two types of leaves. Nest leaves (trophophylls) form the so-called conch, with a diameter of approx. $30 \mathrm{~cm}$. They are responsible for keeping the plants on the tree trunk and enable collection of humus and water, the shortages of which the plant is periodically exposed to. In ontogenesis, their color turns brown, losing assimilation functions, for which sporotrophophylls are responsible. These leaves have a green color, ribbon-like shape, with a distinctive dichotomously forked ending. In addition, they perform the functions associated with spore production. The natural areas of Platycerium occurrence are the tropical forests of Australia and New Guinea, in which tree canopies play a special role in the regulation of lighting, temperature and humidity. The color of the light is substantially modified under natural shading in the deeper layers of the forest (Nadkarni et al., 2004). The low R/FR ratio is caused by absorption of radiation in the blue and red wavelength range by the higher parts of the vegetation. Moreover, the presence of other plants in the vicinity can also modify the spectral composition of light through the phenomena of absorption and reflectance. The multidimensional nature of the plant makes the angle of incidence of sunlight heterogeneous in individual organs (especially leaves). Increased human activity in the zone of tropical forests results in additional intensity fluctuations and changes in spectral composition of light reaching the plants located in the lower forest layers, including epiphytes such as $P$. bifurcatum.

Leaf senescence depends on both genetic and environmental factors (Weaver and Amasino, 2001). It involves changes in the composition of plant pigments present in the leaves that determine tissue color (Merzlyak et al., 2003) and is regulated by the phytochrome mechanism (Behera and Biswal, 1990). Therefore, the result of leaf senescence is its color change, which is a consequence of the process of chlorophyll disintegration and degradation of chloroplast ultrastructure, and the loss of turgor of cells that build the lamina. Both the intense light and shadow can initiate and regulate the rate of leaf senescence, although the mechanism is similar to the natural aging conditioned by species phenology (Causin et al., 2006). In addition, the spectral composition of light with increased content of farred reaching the leaves of plants growing under the canopy, often accelerates the process of leaf senescence. With an increase of the R/FR ratio, an opposite effect is observed, suggesting that this process is controlled by the phytochrome (Biswal and Biswal, 1984)

The aim of this study was to determine the morphological and physiological changes in nest leaves of $P$. bifurcatum occurring during sporophyte ontogenesis, at different values of the $\mathrm{R} / \mathrm{FR}$ ratio in the light spectrum. Appropriately low (L-R/FR) or high (H-R/FR) R/FR value provides information about shading or insolation of the plant. The study used non-destructive methods, which enabled tracking physiological changes within the same leaves. In addition to assessing the photochemical efficiency of the nest leaves, the content of chlorophyll and phenolic compounds 
was estimated. An analysis of the light radiation reflectance from the leaves was also performed, which allowed to describe, inter alia, changes in the content of carotenoids and anthocyanins during leaf senescence. In addition, morphological and anatomical analysis was carried out. Knowledge of the physiology of this species, the course of ontogenetic development and response to changes in abiotic environmental factors may be useful for producers of ornamental plants.

\section{MATERIALS AND METHODS}

\section{PLANT MATERIAL}

The study used 10-month sporophytes of Platycerium bifurcatum (Cav.) C. Chr., derived from the collection of the Pedagogical University in Kraków. Twenty-two plants of similar size were selected, at the same stage of morphological development and divided into two equal groups. Six weeks before the start of the measurements, two groups of plants were placed in a Flowstar Snijders Scientific climate chamber (The Netherlands) equipped with LED lighting, which allowed the emission of radiation at certain wavelengths: 450, 650 and $730 \mathrm{~nm}$. The first group was exposed to radiation with a low red/far-red ratio - L-R/FR, which was simulating shadow conditions. The second group of plants was grown under the light with a high ratio of R/FR (H-R/FR) - simulation of well insolated habitats. These conditions were achieved by limiting the far-red radiation $(730 \mathrm{~nm})$. A slight increase in the intensity of radiation in the blue range allowed compensating for the amount of energy that reached the plants in both groups (Oliwa et al., 2016). All plants were grown at $25^{\circ} \mathrm{C} / 15^{\circ} \mathrm{C}$ with a photoperiod of $16 / 8$ hours (day/ night, respectively). Humidity was constant at $\mathrm{RH}=60 \%$.

\section{MORPHOLOGICAL AND ANATOMICAL ANALYSIS OF THE NEST LEAVES}

The analysis of morphological changes in the nest leaves occurring during sporophyte development was carried out every 7 days for 12 weeks, along with photographic documentation. The range and rate of these changes was compared in plants cultivated in two different spectral conditions.

The analysis of the anatomy was performed on microscope slides in distilled water, representing cross-sections of the leaf lamina using a light microscope and a Nikon ECLIPSE $\mathrm{Ni}$ epifluorescence microscope (Nikon, Japan) equipped with Microscope Camera Digital Sight series DS-Filc and NIS Imaging, Nikon v. 4.11 software. Classification of developmental stages of the nest leaves was compiled on the basis of morphological and anatomical differences.

\section{MEASUREMENTS OF KINETIC PARAMETERS OF CHLOROPHYLL A FLUORESCENCE}

Chlorophyll a fluorescence was measured using a Handy-PEA Hansatech Instruments fluorimeter (UK) according to the method of Strasser et al. (2000). Selected fluorescence parameters were determined: $F_{v} / F_{m}$, Area, $F_{v} / F_{0}$, PI and RC/ABS. In addition, the following parameters of energy flow through PSII were determined: $\mathrm{TR}_{0} / \mathrm{RC}$, $\mathrm{ET}_{0} / \mathrm{RC}, \mathrm{DI}_{0} / \mathrm{RC}$.

Leaf measurements at each development stage were performed on the upper surface of the leaf lamina at $20^{\circ} \mathrm{C}$. A commercial clip equipped with an iris was used for the measurements. The plant was acclimated in the dark for 20 minutes in order to quench the light phase of photosynthesis reaction after mounting the clip. Radiation with an intensity of $3 \mathrm{mmol} \mathrm{m} \mathrm{m}^{-2} \mathrm{~s}^{-1}$ was used for excitation of chlorophyll fluorescence. The measurement results were analyzed using PEA Plus Hansatech Instruments software (UK).

\section{SPOROTROPHOPHYLL SPECTROPHOTOMETRICAL ANALYSIS}

Fluorescence emission spectra of the leaves were obtained using a Perkin Elmer LS55 spectrofluorimeter with external fiber optic accessory based on the method of Lichtenthaler and Schweiger (1998). The measurements were performed on the upper surface of the leaf lamina, in two ranges of radiation: blue-green $(430-650 \mathrm{~nm})$ and red and far-red $(600-800 \mathrm{~nm})$. This provided the possibility of determining the intensity of fluorescence derived from phenolic compounds and chlorophyll, respectively. The analysis included the same leaves at all times. Based on the analysis of the fluorescence spectra obtained by FL WinLab 4.0 software, we calculated the following coefficients for assessing the impact of environmental factors on the metabolism of the plant: F450/F530, F450/F684, F450/F735 and F684/F735 (Schweiger et al., 1996).)The experiment was performed in five replicates for each spectral light composition (L-R/FR and H-R/FR).

\section{ASSESSMENT OF SPOROTROPHOPHYLL OPTICAL PROPERTIES}

The reflectance spectrum of the light radiation in the range of 400-1000 $\mathrm{nm}$ was measured using a CID Bio-Science CI-710 spectrometer (USA) with SpectraSnap software. The measurements were performed for all stages of leaf development. Reflectance coefficients were calculated based 
on the analysis of spectral reflectance - enabling the assessment of changes, during different phases of leaf development, in the content of: anthocyanins, ARI $=\left(\mathrm{R}_{550}{ }^{-1}-\mathrm{R}_{700}{ }^{-1}\right) \times \mathrm{R}_{800}$ (Gitelson et al., 2001); carotenoids, $\mathrm{CRI}_{1}=\left(\mathrm{R}_{520}{ }^{-1}-\mathrm{R}_{550}{ }^{-1}\right) \times \mathrm{R}_{800}$ (Gitelson et al., 2002) and water, WBI $=R_{900} \times\left(R_{970}\right)^{-1}$ (Peñuelas et al., 1993). In addition, browning reflectance index, BRI $=\left(1 / R_{550}-1 / R_{700}\right) / R_{750}$ was calculated for leaves at all developmental stages (Chivkunova et al., 2001). The letter $\mathrm{R}$ in equations is the reflectance intensity at the radiation wavelength given in subscript.

\section{STATISTICAL ANALYSIS}

Statistical analysis was performed using ANOVA implemented in the Statistica 10 software (StatSoft, Poland). The significance of differences was determined at $p \leq 0.05$ using post-hoc HSD Tukey test and Duncan test.

\section{RESULTS AND DISCUSSION}

\section{MORPHOLOGICAL AND ANATOMICAL ANALYSIS OF THE NEST LEAVES}

The principle functions of the nest leaves, i.e., collection of water and minerals and anchoring the plant to the substrate, force different structure and physiology of these organs in comparison with sporotrophophylls (Oliwa et al., 2016). Relatively short, intense growth in the size of the lamina was observed in the development of the nest leaves combined with the formation of characteristic venation and rapid loss of chlorophyll and assimilation properties in browning leaves (Fig. 1). The course of individual processes at a morphological level can be divided into four main stages of development: I - juvenile stage (Figs. 1a-e), II - intensive development stage (Figs. 1a-c and f), III - aging symptoms stage (mosaic leaf; Figs. 1d and e), IV - terminal stage (brown leaf; Fig. 1e). At the first stage (I), the leaf adopts a heart shape with smooth texture, light green color and is covered with a thick tomentose on the upper side of the lamina, which is particularly well visible in Figs. 1d and e. At the end of the stage, darker veins become visible in the base portion of the leaf (Fig. 1e). Stage II is characterized by a rapid increase in the size of the leaf that is becoming intensely green in color with light brown venation on the whole surface. The tomentose covering the leaf disappears. The characteristic bending of the lamina takes place leading to the formation of the conch (Figs. 1b and c). The leaf size at the beginning of stage III is established, signs of tissue aging are visible
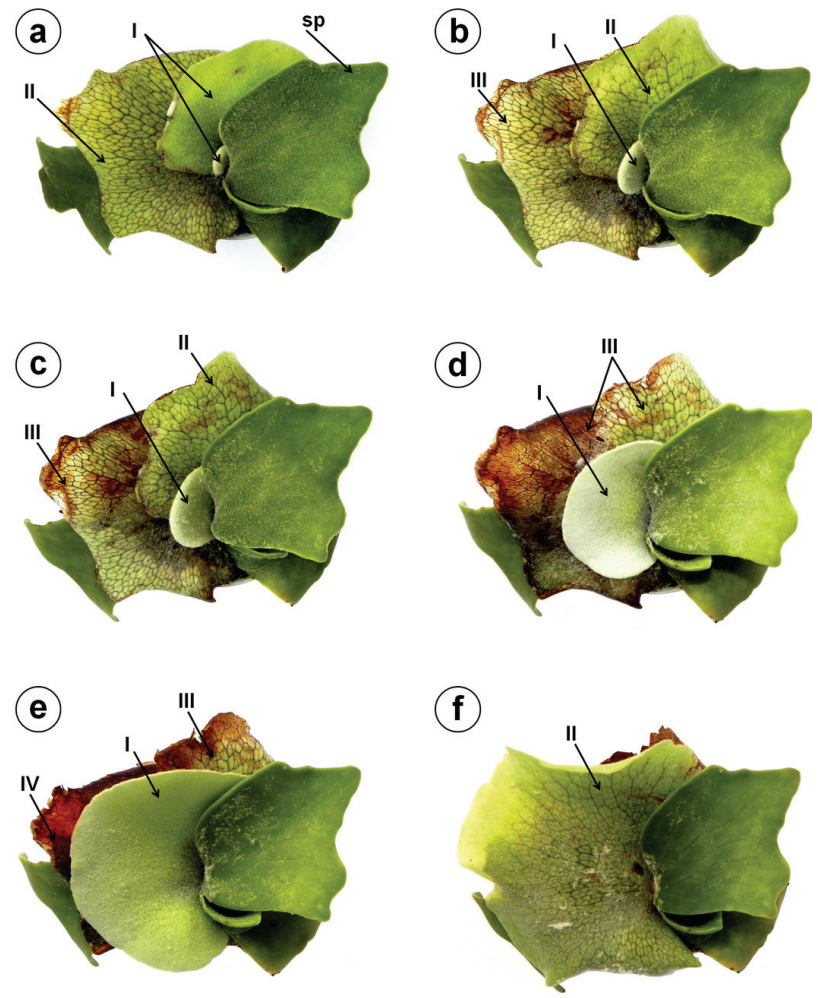

Fig. 1. Developmental stages of nest leaves (I-IV) at subsequent stages of growth of young Platycerium bifurcatum sporophytes (a-f) observed in 14-day intervals for 12 weeks, sp - sporotrophophyll leaf.

and they are associated with the loss of turgor and pigments, resulting in local yellowing and browning of leaves. This gives the characteristic mosaic appearance of the lamina - with alternating green, yellowed and brown areas (Figs. 1c-e). At the terminal stage IV, leaf cells are mostly dead and the lamina becomes brown on the whole surface (Fig. 1d).

The R/FR ratio modifies the process of development and physiological properties of the nest leaves. Although the structural changes occur in a similar manner at both low and high R/FR ratio, the time when particular developmental stages are reached is fundamentally different. In plants growing in the L-R/FR conditions, the rate of ontogenetic development is faster than in those growing under $\mathrm{H}-\mathrm{R} / \mathrm{FR}$. This is demonstrated by different numbers of leaves present at particular stages of development (Table 1). After ten weeks of growth, sporophytes exposed to the L-R/FR radiation had on average more leaves at stages III and IV than younger leaves at stages I and II, suggesting a rapid process of maturation and aging. Under the L-R/FR conditions, leaves at stage 
TABLE 1. The average number of the nest leaves in one specimen of the fern Platycerium bifurcatum in the subsequent stages of sporophyte development at a low (L-R/FR) and high (H-R/FR) radiation ratio of red to far-red, $\mathrm{n}=20$.

\begin{tabular}{|c|c|c|c|c|c|c|c|c|c|c|}
\hline \multirow{3}{*}{$\begin{array}{l}\mathbf{R} / \mathbf{F R} \\
\text { ratio }\end{array}$} & \multirow{3}{*}{$\begin{array}{l}\text { Growth } \\
\text { phase* }\end{array}$} & \multicolumn{9}{|c|}{ Number of leaves/plants } \\
\hline & & \multicolumn{9}{|c|}{ Growth time [weeks] } \\
\hline & & 4 & 5 & 6 & 7 & 8 & 9 & 10 & 11 & 12 \\
\hline \multirow{4}{*}{$\mathrm{L}-\mathrm{R} / \mathrm{FR}$} & I & 2 & 1 & 1 & 1 & 1 & 0 & 0 & 0 & 1 \\
\hline & II & 1 & 2 & 2 & 2 & 1 & 1 & 1 & 1 & 0 \\
\hline & III & 0 & 0 & 0 & 1 & 1 & 2 & 1 & 1 & 1 \\
\hline & IV & 0 & 0 & 0 & 0 & 1 & 1 & 2 & 2 & 3 \\
\hline \multirow{4}{*}{$\mathrm{H}-\mathrm{R} / \mathrm{FR}$} & I & 1 & 1 & 1 & 1 & 1 & 1 & 1 & 1 & 1 \\
\hline & II & 0 & 0 & 0 & 1 & 1 & 1 & 1 & 1 & 1 \\
\hline & III & 0 & 0 & 0 & 0 & 0 & 0 & 1 & 1 & 1 \\
\hline & IV & 0 & 0 & 0 & 0 & 0 & 0 & 0 & 0 & 1 \\
\hline
\end{tabular}

* See more information in the text.

IV appeared as early as in week 8 of growth, while under H-R/FR only in week 12 and in a low number. Thus, in the spectrum with less far-red, leaf growth and tissue aging was delayed. A similar pattern was observed in a study performed in Helianthus annuus (Rousseaux et al., 2000). These authors' results suggested that the increase in R/FR in this species delayed the aging process of the basal leaves before the flowering period. Supplementation of the light spectrum with far-red (reducing the R/FR ratio) in barley slowed the aging process of herbaceous parts of plants (Skinner et al., 1993).

No significant changes were observed in the anatomical structure at the subsequent stages of development of the nest leaves, both at high and low values of the R/FR ratio in the spectrum of light (Fig. 2). The leaves were amphistomatic, vascular bundle was located centrally, sclerenchyma was present on both sides of the bundle. Chloroplasts in the parenchyma at stages I and II were present predominantly in cell layers adjacent to the epidermis (more numerous on the upper side) and around veins (Figs. 2a-b and c-d). At stage III, a significant decrease in the number of chloroplasts in the cells was observed, accompanying the process of senescence (Fig. 2e). At stage IV, a few living chloroplasts were present only in the parenchyma cells directly under the epidermis and around the vascular bundle (Figs. 2f and g). The parenchyma cells located deeper were larger with intercellular spaces, however, compared to the sporotrophophyll leaves, the intercellular spaces were significantly smaller (Oliwa et al., 2016). Such a structure of the parenchyma is associated with the function of collecting and storing water by the young nest
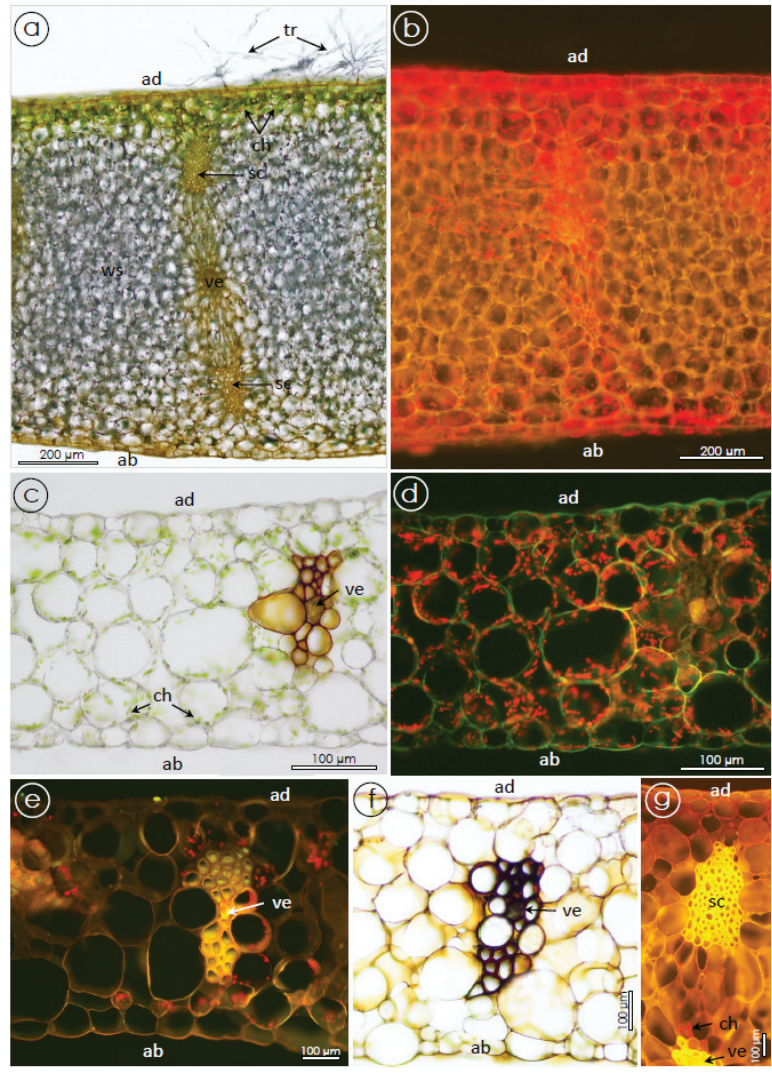

Fig. 2. Cross-section of a nest leaf of Platycerium bifurcatum (the elkhorn fern or the staghorn fern). (a, c, f) observed in transmitted white light, (b, d, e, g) observed using epifluorescence microscopy. (a, b) stage I, (c, d) stage II, (e) stage III, (f, g) stage IV of development of the nest leaves. ab - abaxial, ad - adaxial, ch - chloroplasts, sc - sclerenchyma, tr - trichomes, ve - vein. 
leaves. This was also evidenced by the distribution of chloroplasts in cells at particular stages of leaf growth and development. In turn, reduced photosynthetic activity of the nest leaves did not require expanded intercellular spaces in the mesophyll.

\section{MEASUREMENTS OF KINETIC PARAMETERS OF CHLOROPHYLL A FLUORESCENCE}

The analysis of changes in the parameters of chlorophyll a fluorescence kinetics, using a continuous excitation fluorimetry method (PEA), enables rapid and non-invasive evaluation of the efficiency of light phase photosynthesis, and therefore, it is one of the more commonly used techniques in physiological studies (Maxwell and Johnson, 2000).

Maximum photochemical performance $\left(\mathrm{F}_{\mathrm{v}} / \mathrm{F}_{\mathrm{m}}\right)$ of the nest leaves in plants growing under conditions of simulated shadow, with greater participation of far-red in the light spectrum (L-R/FR) did not change at the next stages of growth, and a significant decrease was observed only at the terminal stage (IV), when the leaves were almost completely devoid of chlorophyll. The values of the $\mathrm{F}_{\mathrm{v}} / \mathrm{F}_{\mathrm{m}}$ parameter at the first two stages of leaf growth of the plants growing under H-R/ FR parameter also did not differ from each other and were similar to those observed under L-R/FR, ranging close to the optimal values (Bjorkman and Demmig, 1987). Under H-R/FR, the number of leaves reaching stages III and IV was so low that it prevented performing a sufficient number of measurements. For this reason, efficiency parameters of PSII in H-R/FR in the aforementioned conditions were not analyzed. Earlier observations of sporotrophophyll leaf development in P. bifurcatum also suggested that the high red/far-red ratio slowed down the processes of morphogenesis of the leaf lamina, even though the nest leaves demonstrated a weaker response to changes in the $\mathrm{R} / \mathrm{FR}$ ratio than sporotrophophylls (Oliwa et al., 2016). Behera and Biswal (1990) indicate that red light delays senescence process in ferns.

The area coefficient describes the amount of energy transferred from the active PSII center to plastoquinone $\mathrm{B}_{\mathrm{A}}$. Area values increased during the growth of the nest leaves (stages I and II - Table 2). The pool of available PSII acceptors at particular stages of development underwent fluctuations, which corresponded to changes in chlorophyll content in the leaves - the highest value was observed at stage II. Since the emergence, a new leaf grows intensively till the venation stage. The latter can be considered as reaching full physiological development, after which gradual extinguishing of metabolic function begins until reaching the terminal stage. Area parameter values reflect the above-described changes (Table 2). The trend of area changes at stages I and II was similar in both spectral configurations, but under L-R/FR, the amount of available $\mathrm{Q}_{\mathrm{A}}$ was higher than in H-R/FR. These observations confirmed previous reports indicating slowing of reactions associated with tissues aging under intensive radiation (Rousseaux et al., 2000).

The activity of the water-splitting complex at the subsequent stages of leaf development, as measured

TABLE 2. The values of chlorophyll $a$ fluorescence parameters in the subsequent growth stages (I-IV) of the nest leaves of Platycerium bifurcatum at a low (L-R/FR) and high (H-R/FR) red/far-red ratio (R/FR). Values in the column marked with the same letters are not significantly different at $p \leq 0.05$ according to Duncan test, $\mathrm{n}=5$.

\begin{tabular}{|c|c|c|c|c|c|c|c|c|c|}
\hline \multirow{2}{*}{$\mathbf{R} / \mathbf{F R}$ ratio } & \multirow{2}{*}{$\begin{array}{l}\text { Growth } \\
\text { phase* }\end{array}$} & \multicolumn{8}{|c|}{ Parameters describing PSII photochemical efficiency } \\
\hline & & $\mathbf{F}_{\mathrm{v}} / \mathbf{F}_{\mathrm{m}}$ & Area & $\mathbf{F}_{\mathrm{v}} / \mathbf{F}_{0}$ & PI & RC/ABS & $\mathrm{TR}_{\mathbf{0}} / \mathrm{RC}$ & $\mathrm{ET}_{0} / \mathrm{RC}$ & $\mathrm{DI}_{0} / \mathrm{RC}$ \\
\hline \multirow{4}{*}{$\mathrm{L}-\mathrm{R} / \mathrm{FR}$} & I & $0.76^{\mathrm{a}}$ & $19506^{c}$ & $3.47^{\mathrm{b}}$ & $1.71^{\mathrm{a}}$ & $0.88^{\mathrm{ab}}$ & $711^{\mathrm{b}}$ & $650^{\mathrm{b}}$ & $244^{\mathrm{a}}$ \\
\hline & II & $0.79^{\mathrm{a}}$ & $31794^{\mathrm{a}}$ & $3.86^{\mathrm{a}}$ & $1.26^{\mathrm{b}}$ & $0.97^{\mathrm{ab}}$ & $1045^{\mathrm{a}}$ & $940^{\mathrm{a}}$ & $236^{\mathrm{a}}$ \\
\hline & III & $0.76^{\mathrm{a}}$ & $19687^{c}$ & $3.16^{\mathrm{b}}$ & $0.56^{\mathrm{c}}$ & $0.62^{\mathrm{b}}$ & $868^{\mathrm{ab}}$ & $802^{\mathrm{ab}}$ & $229^{\mathrm{a}}$ \\
\hline & IV & $0.51^{\mathrm{b}}$ & $1100^{\mathrm{d}}$ & $0.35^{\mathrm{c}}$ & $0.25^{c}$ & $0.18^{c}$ & $10^{c}$ & $13^{c}$ & $14^{\mathrm{b}}$ \\
\hline \multirow{4}{*}{ H-R/FR } & I & $0.77^{\mathrm{a}}$ & $17279^{c}$ & $3.38^{\mathrm{b}}$ & $1.05^{\mathrm{b}}$ & $1.08^{\mathrm{a}}$ & $693^{\mathrm{b}}$ & $645^{\mathrm{b}}$ & $244^{\mathrm{a}}$ \\
\hline & II & $0.76^{\mathrm{a}}$ & $25536^{\mathrm{b}}$ & $3.14^{\mathrm{b}}$ & $1.15^{\mathrm{b}}$ & $0.88^{\mathrm{ab}}$ & $927^{a}$ & $1008^{a}$ & $222^{\mathrm{a}}$ \\
\hline & III & n.d. ${ }^{* *}$ & n.d. ${ }^{* *}$ & n.d. ${ }^{* *}$ & n.d. ${ }^{* *}$ & n.d. $* *$ & n.d. ${ }^{* *}$ & n.d. $* *$ & n.d. ${ }^{* *}$ \\
\hline & IV & n.d. ${ }^{* *}$ & n.d. $* *$ & n.d. ${ }^{* *}$ & n.d. ${ }^{* *}$ & n.d. $* *$ & n.d. ${ }^{* *}$ & n.d. $* *$ & n.d. $* *$ \\
\hline
\end{tabular}

\footnotetext{
* More information in the text.

** Lack plants in these phase of growth.
} 
by the value of the $\mathrm{F}_{\mathrm{v}} / \mathrm{F}_{0}$ parameter, was similar to changes in the maximum photochemical efficiency $\left(\mathrm{F}_{\mathrm{v}} / \mathrm{F}_{\mathrm{m}}\right)$. It significantly increased only at the most intensive stage of leaf development (II) in plants grown under L-R/FR (Table 2). The sharp decline of $\mathrm{F}_{\mathrm{v}} / \mathrm{F}_{0}$ values at stage IV informs about the loss of the acceptor function of part of the PSII reaction centers (Pereira et al., 2000). The PI parameter (PSII vitality) can also be used to determine the inner strength of plants that allows counteracting external stressors. The systematic decline in the PI value of plants growing under L-R/FR is consistent with the discussed trend of the nest leaf development. It is determined by the number of active reaction centers, as well as the quantum yield of photosynthesis and depends on the efficiency of the redox reaction of the dark phase (Strasser et al., 2000, 2004). However, it is interesting that, in contrast to the previously discussed indices, the PI value is the highest in leaves at stage I of growth (Table 2).

Photosynthetic efficiency (RC/ABS) describing the density of reaction centers was reduced between stages III and IV of growth (Table 2). This demonstrated fast processes of chloroplast aging and loss of pigments. Such a correlation of the $\mathrm{RC} / \mathrm{ABS}$ ratio with a loss of chlorophyll was also observed in plants of the genus Oryza (Falqueto et al., 2010).

$\mathrm{TR}_{0} / \mathrm{RC}$ and $\mathrm{ET}_{0} / \mathrm{RC}$ parameters (Table 2), describing the energy captured by one $\mathrm{RC}$ and the speed with which the electrons are transferred by it, confirmed the substantial increase in the photosynthetic activity at stage II of leaf development and subsequent decline associated with senescence. The decrease in chlorophyll content is combined with the $\mathrm{TR}_{0} / \mathrm{RC}$ decline, which was confirmed by the report of Castro et al. (2011). At stages I and II of development, the differences in $\mathrm{TR}_{0} / \mathrm{RC}$ and $\mathrm{ET}_{0} / \mathrm{RC}$ values between the leaves growing under L-R/FR and H-R/FR were statistically insignificant. This indicated, in both cases, the efficient use of reaction centers by leaves and a high ratio of the number of $R C$ to $Q_{A}$, which ensures an appropriate transfer rate of electrons (Stasser et al., 2000). Furthermore, close spatial arrangement of leaf blades and their overlap hinders uniform absorption of radiation by all leaves. Hence, organs less exposed to radiation can react less to differences in the $\mathrm{R} / \mathrm{FR}$ ratio. The $\mathrm{DI}_{0} / \mathrm{RC}$ factor of energy dissipation must also be considered in the context of both of these parameters. The nest leaves are globally characterized by a lower number of RCs than in sporotrophophylls, which is probably due to the lower energy requirements. This is understandable in view of their role and high potential of the dissipating surface. Thus the high value of the parameter is not surprising. As regards the leaves growing under $\mathrm{L}-\mathrm{R} / \mathrm{FR}$, the $\mathrm{DI}_{0} / \mathrm{RC}$ value drastically decreased only at the moment of chlorophyll loss after entering the terminal phase of development.

\section{BLUE-GREEN AND RED LEAF FLUORESCENCE}

Fluorescence spectra of the nest leaves of $P$. bifurcatum growing both under high and low R/FR values had two extremes (Figs. 3a and 3b). In the blue-green spectrum, a clear peak was visible with a maximum at $530 \mathrm{~nm}$ (Fig. 3a). Therefore, the peak maximum is shifted to longer wavelengths compared to the results obtained for the spermatophytes, where the main emission band is typically in the ranges of $430-450 \mathrm{~nm}$ and $520-530 \mathrm{~nm}$ (Stober and Lichtenthaler, 1992; Lichtenthaler and Schweiger, 1998). In P. bifurcatum only a shoulder of the peak was observed in the blue range spectrum, however, changes in the course of fluorescence curves may vary depending on the absorption characteristics of the leaves (Stober and Lichtertahler, 1993; Gitelson et al., 1998). Phenolic compounds (primarily ferulic acid) are located mainly in the epidermal cells and in the area of vascular bundles. The high intensity of blue-green fluorescence in the nest leaves may be associated with their welldeveloped vascular system, and a large lamina surface (Lichtenthaler and Miehe, 1997; Buschmann and Lichtenthaler, 1998).

There are two peaks of fluorescence emission in the majority of plants in the range of red and farred, at a wavelength of $735 \mathrm{~nm}$ and 685-690 nm. Fluorescence in this range is dependent on the presence of chlorophyll building reaction centers and PS II antenna complexes (Gitelson et al., 1998; Hall and Rao, 1999). One major peak was observed in the nest leaves of $P$. bifurcatum at $684 \mathrm{~nm}$ (Fig. 3b). A maximum at the same wavelength was also obtained by Eullaffroy and Vernet (2003) in their study on algae. Therefore, when calculating fluorescence coefficients describing the physiological state of the plant, the value of fluorescence intensity at $684 \mathrm{~nm}$ was included instead of the fluorescence intensity at $690 \mathrm{~nm}$, as suggested by many authors.

In the far-red $(735 \mathrm{~nm})$, a clear shoulder was observed in the peak of leaf red fluorescence at stage I in the leaves growing under L-R/FR, while under H-R/FR during stages I and II (Fig. 3b). The peak of L-R/FR, along with the change in leaf development stage, showed a gradual decrease in fluorescence intensity at $684 \mathrm{~nm}$ (virtually to zero at stage IV) and the disappearance of the shoulder at $735 \mathrm{~nm}$ already between stages I and II. However, differences in the intensity and shape of fluorescence peaks in the leaves at stages I and II under H-R/FR were virtually unnoticeable (Fig. 3b). This confirmed earlier observations obtained in this 

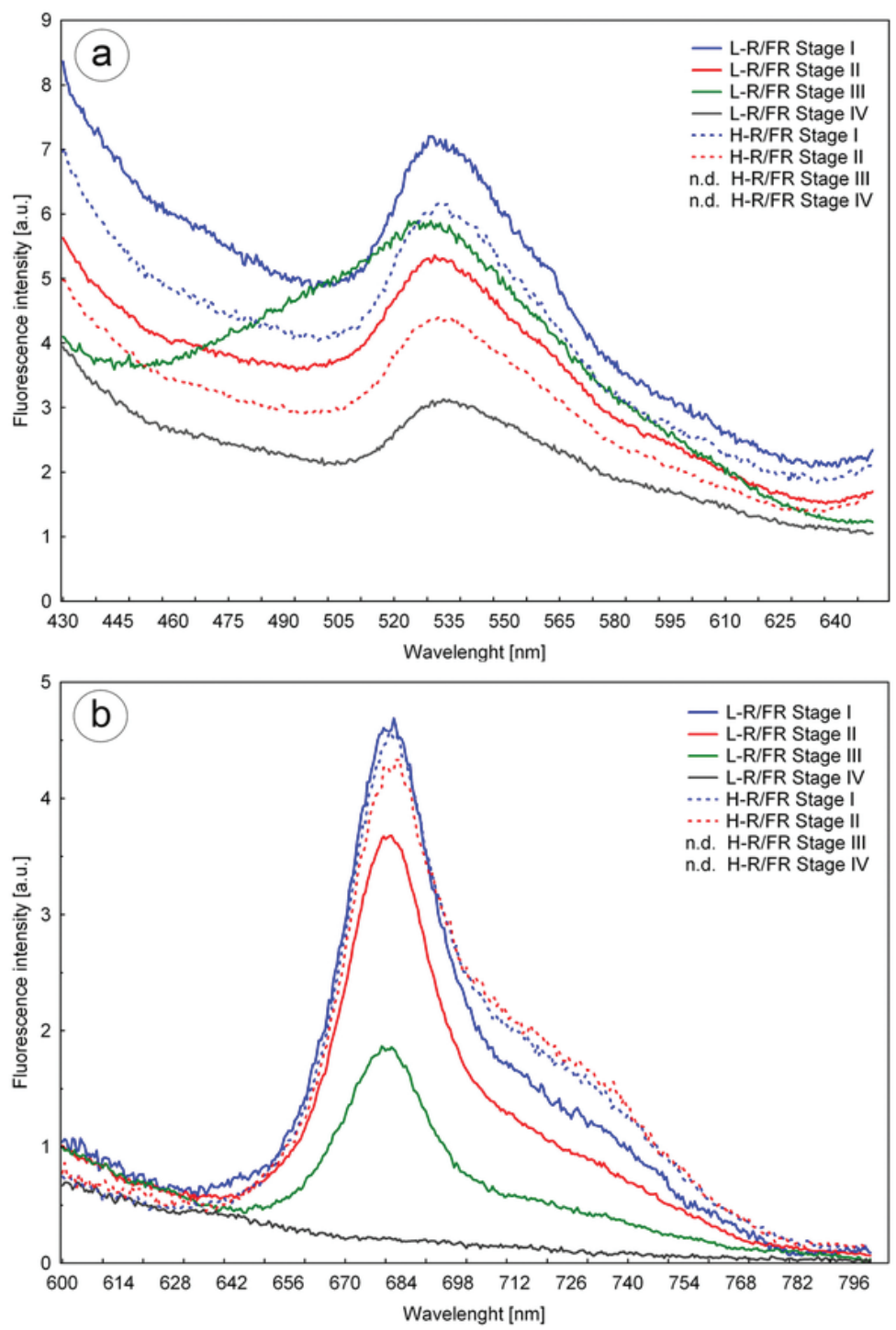

Fig. 3. Blue-green (a) and red (b) fluorescence spectra of nest leaves of Platycerium bifurcatum at subsequent stages (I-IV) of development at a low (L-R/FR) and high (H-R/FR) R/FR ratio in the light spectrum. The curves represent mean values of 5 replicates.

study indicating that the metabolic changes occur more slowly in the leaves growing under H-R/FR.

The overall shape of the spectrum and the wavelengths of the main bands of fluorescence in the nest leaves of $P$. bifurcatum, both in the blue-green and red spectrum, were similar to the sporotrophophyll leaves (Oliwa et al., 2016).

In photosynthetic organisms, the value of F450/F530 coefficient is positively correlated with phenolic compound contents. It was shown that changes in the F450/F530 could explain up to $80 \%$ of changes in the content of phenols (Kula et al., 2016). Changes in the F450/F530 ratio at different stages of leaf development suggest that phenolic compound contents were very similar both under L-R/FR and H-R/FR at stages I and II (Table 3). Phenolic contents in the leaves grown under L-R/FR were reduced at stage III and increased again at the terminal stage of growth (IV). Changes in the content of phenolic compounds in the leaf epidermis are related to the protection of the photosynthetic apparatus from damage due to excessive radiation (Bilger et al., 2001). The decrease in the content of phenols at stage III of growth may result from decreasing photosynthetic activity of the leaves, as indicated, inter alia, by a significant decrease in the number of chloroplasts in the cells (Fig. 2e), while the increase in the content of phenols at stage IV can 
Table 3. The values of fluorescence parameters in the subsequent growth stages (I-IV) of the nest leaves of Platycerium bifurcatum at a low (L-R/FR) and high (H-R/FR) red/far-red ratio (R/FR). Values in the column marked with the same letters are not significantly different at $p \leq 0.05$ according to Duncan test, $\mathrm{n}=5$.

\begin{tabular}{|c|c|c|c|c|c|}
\hline \multirow{2}{*}{$\begin{array}{l}\mathrm{R} / \mathrm{FR} \\
\text { ratio }\end{array}$} & \multirow{2}{*}{ Growth phase* } & \multicolumn{4}{|c|}{ Fluorescence ratios } \\
\hline & & F450/F530 & F450/F684 & F450/F735 & F684/F735 \\
\hline \multirow{4}{*}{ L-R/FR } & I & $0.906^{\mathrm{ab}}$ & $1.430^{\mathrm{a}}$ & $6.241^{\mathrm{a}}$ & $3.638^{\mathrm{a}}$ \\
\hline & II & $0.830^{\mathrm{b}}$ & $1.324^{\mathrm{a}}$ & $6.306^{\mathrm{a}}$ & $3.375^{\mathrm{a}}$ \\
\hline & III & $0.644^{c}$ & $2.011^{\mathrm{a}}$ & $5.734^{\mathrm{a}}$ & $2.906^{\mathrm{a}}$ \\
\hline & IV & $0.954^{\mathrm{a}}$ & n.d. ${ }^{* *}$ & n.d.** & n.d.** \\
\hline \multirow{4}{*}{ H-R/FR } & I & $0.881^{\mathrm{ab}}$ & $1.589^{\mathrm{a}}$ & $3.796^{b}$ & $2.237^{\mathrm{a}}$ \\
\hline & II & $0.855^{\mathrm{ab}}$ & $0.790^{\mathrm{a}}$ & $2.033^{\mathrm{b}}$ & $2.553^{\mathrm{a}}$ \\
\hline & III & n.d. ${ }^{* * *}$ & n.d. $* * *$ & n.d.*** & n.d. ${ }^{* * *}$ \\
\hline & IV & n.d. ${ }^{* * *}$ & n.d. ${ }^{* * *}$ & n.d. ${ }^{* * *}$ & n.d. ${ }^{* * *}$ \\
\hline
\end{tabular}

* More information in the text.

** Lack Chl in leaves in these phase of development.

${ }^{* * *}$ Lack plants in these phase of growth.

be associated with the role of phenols as chemical compounds "preserving" the conch leaves and protecting them against pathogens. However, this assumption should be confirmed in further studies.

The values of F450/F684 and F450/F735 coefficients are important sensors of early plant's reaction, depending on the external environment, showing changes in metabolic activity of the leaves (Buschmann and Lichtenthaler, 1998; Schweiger et al., 1996). The values of $\mathrm{F} 450 / \mathrm{F} 684$ did not change significantly either in the leaves grown under L-R/FR or H-R/FR (Table 3). Similarly, the values of F450/F735 were unaffected at subsequent stages of growth both in the leaves growing at the low and high R/FR ratio, although the values of F450/F735 under H-R/FR were lower than those reached by the plants under L-R/FR (Table 3).

The F684/F735 ratio calculated based on the fluorescence of red and far-red allows determining the change in the quantity of chlorophyll during the plant's growth, because its value is inversely proportional to the content of this pigment in the leaves (Gitelson et al., 1998). At stage IV, there was no clear maximum corresponding to $735 \mathrm{~nm}$, thereby calculating the F684/F735 did not give reliable results. This was caused by too low chlorophyll content. In the case of juvenile and intensive developmental stages, chlorophyll content in the young and in the fully expanded leaves was similar both under L-R/FR and H-R/FR.

\section{LEAF REFLECTANCE ANALYSIS}

Point reflectance measurement enables the assessment of pigment composition of a single leaf, without disturbances occurring when measuring radia- tion reflectance of the stand (as a result of its complex geometric structure - Linke et al., 2008). The high intensity of the reflectance of light in the green range of the spectrum is associated with the presence of photosynthetic pigments, especially chlorophylls (Gitelson et al., 2001). The values of the reflectance radiation of the nest leaves at stages I and II depended on the value of the R/FR ratio (Fig. 4) and thus, the leaves grown under L-R/ FR (solid blue and red lines) showed higher reflectance values than those growing under H-R/FR (dashed lines, blue and red, respectively). High reflectance values in the PAR range are due to lower chlorophyll content in the leaf area (Moran et al., 2000; Araus et al., 2001). These differences between the leaves are particularly visible at stage II of development (Fig. 4). This observation indicated accelerated senescence of the leaves growing under L-R/ FR. At all stages of plant's growth in the light, the maximum chlorophyll content is controlled by phytochromes. Red light increases the total chlorophyll content (Jedynak et al., 2001). Therefore, the lower chlorophyll content in L-R/FR conditions was not surprising. A significant reduction in reflectance intensity at stage III and the complete lack of peaks at stage IV observed in the L-R/FR spectrum reflected the process of leaf senescence. It was associated with a modification of their structure and function and loss of photosynthetic capacity. Reflectance of leaves at stage IV resembles the spectrum of reflectance derived from the soil (Araus et al., 2001).

Chemical analysis methods used to determine the content of anthocyanins and carotenoids in plant tissues are destructive, relatively low sensitive, and sometimes they are burdened with additional errors due to the instability of pigments, 


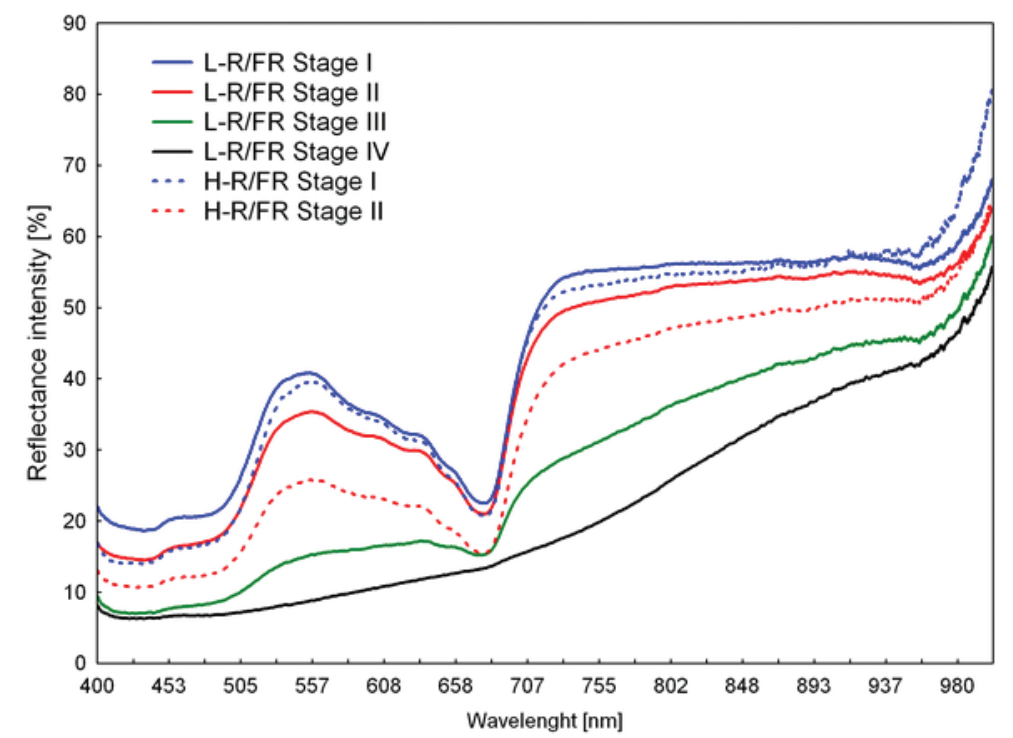

Fig. 4. Light radiation reflectance curves of Platycerium bifurcatum nest leaves at subsequent stages (I-IV) of development at a low (L-R/FR) and high (H-R/FR) red/far red ratio (R/FR) in the light spectrum. The mean values of 5 replicates.

and therefore, the use of optical spectroscopy is a good alternative to the classical analysis (Peñuelas and Filella, 1998; Gamon and Surfus, 1999; Gitelson et al., 2001; Solovchenko, 2010).

The content of anthocyanins (ARI) and carotenoids $\left(\mathrm{CRI}_{1}\right)$ in the leaves as well as hydration (WBI) and the value of browning reflectance index (BRI) are shown in Table 4. The ARI coefficient increases linearly with increasing content of anthocyanins in the leaf tissue (Gitelson et al., 2001; Steele et al., 2009). Anthocyanin content estimated on the basis of ARI showed the increase of pigments between stage I and stage II, regardless of the value of the $\mathrm{R} / \mathrm{FR}$ ratio. In the case of plants growing under L-R/FR, an increase in the intensity of reflectance derived from anthocyanins was observed during the aging process (mosaic leaf stage - stage III). With a drop in chlorophyll content (e.g., during leaf senescence), plants use anthocyanins to protect the photosynthetic apparatus, more susceptible to environmental stress than in younger leaves with a higher chlorophyll content (Hoch et al., 2001; Feild et al., 2001; Cooney et al., 2015). In fact, the amount of anthocyanins is correlated with the degree of chlorophyll degradation (Anderson and Ryser, 2015). Increased synthesis of anthocyanins de novo during leaf senescence has been described in many plants, and the contents of the aforementioned pigments depend on the species (Lee, 2002). In the case of $P$. bifurcatum, it is not related to species phenology, but it seems to be the result of ontogenetic development of the plant. Fast senescence of the nest leaves is in fact a natural and desirable process.
The content of carotenoids in the leaf increases proportionally to the $\mathrm{CRI}_{1}$ parameter value (Solovchenko, 2010). A significant increase in $\mathrm{CRI}_{1}$ for both L-R/FR and H-R/FR was observed between stages I and II, at the time of intensive development of the nest leaves, but it was significantly higher in plants growing under H-R/FR (Table 4). Further intensive increase in the amount of carotenoids in the tissue was shown during the process of intensive senescence (stages III and IV) of leaves growing under L-R/FR, similarly as for anthocyanins. Carotenoids play a key role in protecting the photosynthetic apparatus by dissipating the excess energy in the xanthophyll cycle (Peterman et al., 1997). Thus, it is not surprising that in plants growing at high R/FR values, characteristic of well insolated habitats, $\mathrm{CRI}_{1}$ values were significantly higher than those observed in plants growing under L-R/FR. In many species, the overall level of carotenoids remains relatively stable during leaf senescence, when the chlorophyll is rapidly degraded, but the carotenoid profile is changing. This affects the functioning of the xanthophyll cycle and violaxantine-zeaxanthin metabolic pathway (Kar et al., 1993). The increase in the CRI ${ }_{1}$ value between stages II and III under L-R/FR suggests a light-dependent (related to phytochrome mechanisms) delay of carotenoid loss during leaf senescence in order to ensure appropriate photoprotection (Biswal, 1995). During leaf senescence there is often an imbalance between the supply of energy absorbed by the plant and the energy demand in the Calvin-Benson cycle (Bukhov, 1997; Lu and Zhang, 1998). 
TABLE 4. The values of reflectance parameters in the subsequent growth stages (I-IV) of the nest leaves of Platycerium bifurcatum at a low (L-R/FR) and high (H-R/FR) red/far-red ratio (R/FR). Values in the column marked with the same letters are not significantly different at $p \leq 0.05$ according to Duncan test, $\mathrm{n}=5$.

\begin{tabular}{|c|c|c|c|c|c|}
\hline \multirow{2}{*}{$\begin{array}{l}\text { R/FR } \\
\text { ratio }\end{array}$} & \multirow{2}{*}{ Growth phase* } & \multicolumn{4}{|c|}{ Reflectance factor } \\
\hline & & ARI & $\mathrm{CRI}_{1}$ & WBI & BRI \\
\hline \multirow{4}{*}{ L-R/FR } & I & $0.01^{\mathrm{c}}$ & $0.010^{\mathrm{d}}$ & $0.97^{\mathrm{b}}$ & $0.0000^{c}$ \\
\hline & II & $0.24^{\mathrm{b}}$ & $0.013^{c}$ & $1.07^{\mathrm{a}}$ & $0.0001^{c}$ \\
\hline & III & $1.12^{\mathrm{a}}$ & $0.021^{\mathrm{ab}}$ & $0.90^{\mathrm{bc}}$ & $0.0008^{\mathrm{b}}$ \\
\hline & IV & $1.23^{\mathrm{a}}$ & $0.018^{\mathrm{b}}$ & $0.80^{\mathrm{d}}$ & $0.0027^{\mathrm{a}}$ \\
\hline \multirow{4}{*}{ H-R/FR } & I & $0.05^{c}$ & $0.014^{c}$ & $0.92^{c}$ & $0.0000^{c}$ \\
\hline & II & $0.30^{\mathrm{b}}$ & $0.023^{\mathrm{a}}$ & $0.97^{\mathrm{b}}$ & $0.0001^{c}$ \\
\hline & III & n.d.** & n.d. $* *$ & n.d. $* *$ & n.d. ${ }^{* *}$ \\
\hline & IV & n.d. ${ }^{* *}$ & n.d. $* *$ & n.d. $* *$ & n.d. $* *$ \\
\hline
\end{tabular}

* More information in the text.

** Lack plants in these phase of growth.

The absorption of radiation by water in the range of $950-970 \mathrm{~nm}$ is weaker than in the infrared range, which causes that the reflectance does not reach the saturation point (maximum absorption values) even in the moderately dry leaf. Therefore, the value of reflectance at $970 \mathrm{~nm}$ can be used to determine the rate of hydration (WBI) (Peñuelas et al., 1993). Structural changes during leaf senescence are associated with decreased tissue turgor. The WBI parameter is a useful indicator of water content in the leaves (Peñuelas et al., 1993; Sims and Gamon, 2003). Numerous studies have shown that the decrease in leaf water content results in the lower WBI parameter (Serrano et al., 2000; Pu et al., 2003). The state of tissue hydration reflected ontogenetic changes both in plants growing in the L-R/FR and H-R/FR spectrum. A significant increase of WBI for L-R/FR, and no change for $\mathrm{H}-\mathrm{R} / \mathrm{FR}$ was recorded during the intensive growth of the size of the leaf lamina (stages I and II) (Table 4). WBI decrease occurred at the beginning of senescence (stage III), and reached a minimum atstage IV. This seems to be a natural consequence of leaf tissue necrosis and reduction in the efficiency of symplastic water transport.

Browning of part or the entire lamina is one of the symptoms of leaf senescence, which induces a change in the reflectance spectrum. The degree of tissue browning can be estimated on the basis of BRI (Chivkunova et al., 2001). BRI values are close or equal to zero regardless of the spectral composition of light at the first and second stage of the nest leaf growth (Table 4). The rate of browning is rapidly increasing in the initial senescence stage (stage III), reaching a maximum at the terminal stage, when the entire lamina turns brown. It is associated with polyphenol accumulation during leaf senescence (Merzlyak et al., 1997; Merzlyak et al., 2003). The loss of cellular compartments and oxidation of polyphenolic compounds together with the polymerization of melanin-like pigments gives brown tissue coloration (Vaughn and Duke, 1984; Butt, 1985). Similar phenomena may occur in stresses, such as injury or superficial scald (Merzlyak et al., 1990; Chivkunova et al., 2001). The BRI parameter confirmed the clear separation, described based on morphological and anatomical analysis, of the process of formation of the final structure of the nest leaves at the growth stage (stages I and II) and senescence and loss of assimilation capacity (stages III and IV).

\section{CONCLUSIONS}

The ratio of $\mathrm{R} / \mathrm{FR}$ in the spectrum of white light regulates morphogenesis of the nest leaves of the fern $P$. bifurcatum. At a high $\mathrm{R} / \mathrm{FR}$ ratio, nest leaves reach the terminal stage of development significantly more slowly. Leaves growing at a low $\mathrm{R} / \mathrm{FR}$ ratio, show high values of PAR reflection that is the result of lower chlorophyll content in the leaf area. During leaf senescence at low R/FR ratio there was a significant increase in the amount of carotenoids and anthocyanins in the tissues and accumulation of polyphenol compounds. The leaves growing in both spectra of light do not differ in anatomical structure. 


\section{AUTHORS' CONTRIBUTIONS}

AS and AK designed the research; JO, AS, AK conducted the research and analyzed the data; JO wrote the paper; AS and AK had primary responsibility for the final content. The authors declare no conflict of interest.

\section{REFERENCES}

ANDERSON R, and RYSER P. 2015. Early autumn senescence in red maple (Acer rubrum L.) is associated with high leaf anthocyanin content. Plants 4: 505-522.

Araus JL, Casadesus J, and BorT J. 2001. Recent tools for the screening of physiological traits determining yield. In: Reynolds MP, Ortiz-Monasterio JI, McNab A [ed.] Application of physiology in wheat breeding, 59-77. CIMMYT, Mexico.

BEHERA YN, and BiswaL B. 1990. Leaf senescence in fern: effect of duration, intensity and quality of light. Environmental and Experimental Botany 30: 181-186.

Bilger W, Johnsen T, and Schreiber U. 2001. UV-excited chlorophyll fluorescence as a tool for the assessment of UV-protection by the epidermis of plants. Journal of Experimental Botany 52: 2007-2014.

BisWAL UC, and BisWAL B. 1984. Photocontrol of leaf senescence. Photochemistry and Photobiology 39: 875-879.

Biswal B. 1995. Carotenoid catabolism during leaf senescence and its control by light. Photochemistry and Photobiology: B Biology 30: 3-14.

BJöRkman O, and Demming B. 1987. Photon yield of $\mathrm{O}_{2}$ evolution and chlorophyll fluorescence characteristics at $77 \mathrm{~K}$ among vascular plants of diverse origins. Planta 170: 489-504.

BRIGGS WR, and Olney MA. 2001. Photoreceptors in plant photomorphogenesis to date: five phytochromes, two cryptochromes one phototropin, and one superchrome. Plant Physiology 125: 85-88.

BuKhov NG. 1997. Leaf senescence: an evaluation of limiting steps in photosynthesis by means of chlorophyll fluorescence-quenching coefficients and P700 redox changes in leaves. Russian Journal of Plant Physiology 44: 303-310.

Buschmann C, and Lichtenthaler HK. 1998. Principles and characteristics of multi-colour fluorescence imaging of plants. Journal of Plant Physiology 152: 297-314.

ButT VS. 1985. Oxygenation and oxidation in the metabolism of aromatic compounds. Annual Proceedings of the Phytochemical Society of Europe 25: 349-365.

Castro FA, Campostrini E, Toress Netto A, and Viana LH. 2011. Relationship between photochemical efficiency (JIP-Test Parameters) and portable chlorophyll meter readings in papaya plants. Brazilian Journal of Plant Physiology 23: 295-304.

Causin HF, Jauregui RN, and Barneix AJ. 2006. The effect of light spectral quality on leaf senescence and oxidative stress in wheat. Plant Science 171: 24-33.

Chivkunova OB, Solovchenko AE, Sokolova SG, Merzlyak MN, Reshetnikova IV, and Gitelson AA. 2001. Reflectance spectral features and detection of superficial scald-in- duced browning in storing apple fruit. Russian Journal of Phytopathology 2: 73-77.

Cooney LJ, Schaefer HM, Logan BA, Co B, and Gould KS. 2015. Functional significance of anthocyanins in peduncles of Sambucus nigra. Environmental and Experimental Botany 119: 18-26.

Eullaffroy P, and Vernet G. 2003. The F684/F735 chlorophyll fluorescence ratio: a potential tool for rapid detection and determination of herbicide phytotoxicity in algae. Water Research 37: 1983-1990.

Falgueto AR, Silva FSP, Cassol D, Magalhães Júnior AM, OlIVEIRA AC, and BACARIN MA. 2010. Chlorophyll fluorescence in rice: probing of senescence driven changes of PSII activity on rice varieties differing in grain yield capacity. Brazilian Journal of Plant Physiology 22: 35-41.

Feild TJ, LEe DW, and Holbrook MN. 2001. Why leaves turn red in autumn. The role of anthocyanins in senescing leaves of red-osier dogwood. Plant Physiology 127: 566-574.

GAMON JA, and Surfus JS. 1999. Assessing leaf pigment content and activity with a reflectometer. New Phytologist 143: 105-116.

Gitelson A, Buschmann C, and Lihtentahler HK.1998. Leaf chlorophyll fluorescence corrected for re-absorption by means of absorption and reflectance measurements. Journal of Plant Physiology 152: 283-296.

Gitelson AA, Merzylak MN, and Chivkunova OB. 2001. Optical properties and nondestructive estimation of anthocyanin content in plant leaves. Photochemistry and Photobiology 71: 38-45.

Gitelson AA, Zur Y, Chivkunova OB, and Merzylak MN. 2002. Assessing carotenoid content in plant leaves with reflectance spectroscopy. Photochemistry and Photobiology 75: 272-281.

Hall DO, and RaO KK. 1999. Photosynthesis (sixth edition). Cambridge University Press, Cambridge.

Hoch WA, Zeldin EL, and McGown BH. 2001. Physiological significance of anthocyanins during autumnal leaf senescence. Tree Physiology 21: 1-8.

JedynaK P, StRZALKA K, and MALEC P. 2014. Light regulation of chlorophyll biosynthesis in angiosperm plants: the role of photoreceptors and the photomorphogenesis repressor COP1, In: Golovko TK, Gruszecki WI, Prasad MNV, Strzałka K. [eds.] Photosynthetic pigments: chemical structure, biological function and ecology, 86-107. Syktyvkar.

KADOTA A, and WADA M. 1999. Red light-aphototropic (rap) mutants lack red light-induced chloroplast relocation movement in the fern Adiantum capillus-veneris. Plant and Cell Physiology 40: 238-247.

Kar M, Streb P, Hertwig B, and Feierabend J. 1993. Sensitivity to photodamage increases during senescence in excised leaves. Journal of Plant Physiology 141: 538-544.

Kraepiel Y, Agnès C, Thiery L, Maldiney R, Miginiac E, and Delaure M. 2001. The growth of tomato (Lycopersicon esculentum Mill.) hypocotyls in the light and in darkness differentially involves auxin. Plant Science 161: 1067-1074.

Kawai H, Kanegae T, Christensen S, Kiyosue T, Sato Y, ImaiZUMI T, KADOTA A, and WADA M. 2003. Responses of ferns to red light are mediated by an unconventional photoreceptor. Nature 421: 287-290. 
KendRICK RE, and KronenBerg GHM. 1994. Photomorphogenesis in plants. Kulwer Adacemic Publishers, Dordrecht.

Kircher S, Kozma-Bognar L, Kim L, AdAm E, Harter K, SCHÄFER E, and NAGY F. 1999. Light quality-dependent nuclear import of the plant photoreceptors phytochrome A and B. Plant Cell 11: 1445-1456.

Kodis G, Herrero C, Palacios R, Mariño-Ochoa E, Gould S, Grondelle R, Gust D, Moore TA, Moore AL, and KenNIS JTM. 2004. Light harvesting and photoprotective functions of carotenoids in compact artificial photosynthetic antenna designs. Journal of Physical Chemistry 108: 414-425.

Kula M, RYs M, SAJA D, Tys J, and Skoczowski A. 2016. Far reddependent changes in the chemical composition of Spirulina platensis. Engineering of Life Science 16: 777-785.

LEE DW. 2002. Anthocyanins in autumn leaf senescence. Advances in Botanical Research 37: 147-165.

Lichtenthaler HK, and Schweiger J. 1998. Cell wall bound ferulic acid the major substance of the blue-green fluorescence emission of plants. Journal of Plant Physiology 152: 272-282.

LiChTENTHALER HK, and MieHE JA. 1997. Fluorescence imaging as a diagnostic tool for plant stress. Trends in Plant Sciences 2: 316-320.

Linke R, SCHNEIDER W, and WeiHS P. 2008. Occurrence of repeated drought events: can repetitive stress situations and recovery from drought be traced with leaf reflectance. Periodicum Biologorum 110: 219-229.

Lu C, and Zhang J. 1998. Changes in photosystem II function during senescence of wheat leaves. Physiologia Plantarum 104: 239-247.

MAXwell K, and Johnson GN. 2000. Chlorophyll fluorescence - a practical guide. Journal of Experimental Botany 51: 659-668.

Merzlyak MN, Gitelson AA, Chivkunova OB, Solovchenko AE, and Pogosyan SI. 2003. Application of reflectance spectroscopy for analysis of higher plant pigments. Russian Journal of Plant Physiology 50: 785-792.

Merzlyak MN, Chivkunova OB, and RyBaKova NI. 1990. Reflectance spectra of potato tuber discs as related to wounding, infection with Phytophthora infestans and treatment with arachidonic acid. Moscow Univeristy Soil Science Bulletin 1: 26-32.

Merzlyak Mn, Gitelson AA, Pogosyan Si, Chivkunova OB, LeKhimena L, Garson M, BuZulukova NP, Shevyryova VV, and RuMYANTSEVA VB. 1997. Reflectance spectra of plant leaves and fruits during their development, senescence and under stress. Russian Journal of Plant Physiology 44: 614-622.

Moran JA, Mitchell AK, Goodmanson G, and Stockburger KA. 2000. Differentiation among effects of nitrogen fertilization treatments on conifer seedlings by foliar reflectance: a comparison of methods. Tree Physiology 20: 1113-1120.

NAdKARni NM, PARKer GG, Rinker HB, and JarZen DB. 2004. The nature of forest canopy. In: Lowman MD, Rinker HB (ed) Forest Canopies, 3-10. Academic Press, USA.

NefF MM, FANKHAUSER C, and Chory J. 2000. Light: an indicator of time and place. Genes and Development 14: 257-271.

Oliwa J, Kornas A, and Skoczowski A. 2016. Morphogenesis of sporotrophophyll leaves in Platycerium bifurcatum de- pends on the red/far-red ratio in the light spectrum. Acta Physiologiae Plantarum 38: 247.

PEÑUElAS J, and Filella I. 1998. Visible and near-infrared reflectance techniques for diagnosing plant physiological status. Trends in Plant Science 3: 151-156.

Peñuelas J, Filella I, Biel C, Serrano L, and Save R. 1993. The Reflectance at the 950-970 region as an indicator of plant water status. International Journal of Remote Sensing 14: 1887-1905.

Pereira We, Sigueira DL, Martínez CA, and Puiatti M. 2000. Gas exchange and chlorophyll fluorescence in four citrus rootstocks under aluminium stress. Journal of Plant Physiology 157: 513-520.

Peterman EJG, Gradinaru CC, Calkoen F, Borst JC, van Grondelle R, and van Amerongen H. 1997. Xanthophylls in light-harvesting complex II of higher plants: light harvesting and triplet quenching. Biochemistry 36: 12208-12215.

PonTing CP, and ARAvind L. 1997. PAS: a multifunctional domain family comes to light. Current Biology 7: 674-677.

Pu R, Ge S, Kelly NM, and Gong P. 2003. Spectral absorption features as indicators of water status in coast live oak (Quercus agrifolia) leaves. International Journal of Remote Sensing 24: 1799-1810.

Rösler J, JAedicke K, and Zeidler M. 2010. Cytoplasmic phytochrome action. Plant and Cell Physiology 51: 1248-1254.

Rousseaux MC, Hall AJ, and Sanchez RA. 2000. Basal leaf senescence in a sunflower (Helianthus annuus L.) canopy: Responses to increased R/FR ratio. Physiologia Plantarum 110: 477-477.

SCHAEFER E, and NAGY F. 2006. Photomorphogenesis in plants and bacteria. Function and signal transduction mechanism. 3rd Edition, Springer, Berlin.

Schweiger J, LANG M, and Lichtenthaler HK. 1996. Differences in fluorescence excitation spectra of leaves between stressed and non-stressed plants. Journal of Plant Physiology 148: 537-547.

Serrano L, Ustin SL, Roberts DA, Gamon JA, and Peñuelas J. 2000. Deriving water content of chaparral vegetation from AVIRIS data. Remote Sensing of Environment 74: 570-581.

Sims DA, and GAMON JA. 2003. Estimation of vegetation water content and photosynthetic tissue area from spectral reflectance: a comparison of indices based on liquid water and chlorophyll absorption features. Remote Sensing of Environment 84: 526-537.

SkinNER RH, and Simmons SR. 1993. Modulation of leaf elongation, tiller appearance and tiller senescence in spring barley by far-red light. Plant Cell and Environment 16: 555-562.

Solovchenko A. 2010. Quantification of screening pigments and their efficiency in situ. In: Solovchenko A [ed.], Photoprotection in plants. Springer Ser. in Biophysics 14, Springer-Verlag Berlin, Heidelberg.

Steele M, Gitelson A, Rundguist D, and Merzlyak M. 2009. Nondestructive estimation of anthocyanin content in grapevine leaves. American Journal of Enology and Viticulture 60: 87.

Stober F, and Lichtenthaler HK. 1992. Changes of the laserinduced blue, green and red fluorescence signatures 
during greening of etiolated leaves of wheat. Plant Physiology 140: 673-680.

Stober F, and LichtenthaleR HK. 1993. Characterisation of the laser-induced blue, green and red fluorescence signatures of leaves of wheat and soybean leaves grown under different irradiance. Physiologia Plantarum 88: 696-704.

Strasser RJ, Srivastava A, and Tsimilli-Michael M. 2000. The fluorescence transient as a tool to characterize and screen photosynthetic samples. In: Yunus M, Pathre U and Mohanty P [ed.], Probing photosynthesis: mechanism, regulation and adaptation, Chapter 25, 443-480. Taylor and Francis, London.

Strasser RJ, Tsimilli-Michael M, and Srivastava A. 2004. Analysis of the chlorophyll $a$ fluorescence transient. In: Papageorgiou GC, Govindjee [ed.], Chlorophyll a fluores- cence: A signature of photosynthesis, 321-362. Springer, Netherlands.

VAughN KC, and DuKE SO. 1984. Function of polyphenol oxidase in higher plants. Physiologia Plantarum 60: 106-112.

WADA M. 1988. Chloroplast photoorientation in enucleated fern protonemata. Plant and Cell Physiology 29: 1227-1232.

WeAVER LM, and Amasino RM. 2001. Senescence is induced in individually darkened Arabidopsis leaves, but inhibited in whole darkened plants. Plant Physiology 127: 876-886.

YAMAGUChI R, NAKAmURA M, MochizUKi N, Kay SA, and NAGATANI A. 1999. Light-dependent translocation of a phytochrome B-GFP fusion protein to the nucleus in transgenic Arabidopsis. Journal of Cell Biology 145: 437-445. 